\title{
Using operations research to enhance delivery of postpartum/ postabortion family planning services in the Arab region
}

Frontiers in Reproductive Health

Follow this and additional works at: https://knowledgecommons.popcouncil.org/departments_sbsr-rh

Part of the International Public Health Commons, Maternal and Child Health Commons, Obstetrics and Gynecology Commons, Social and Behavioral Sciences Commons, and the Women's Health Commons How does access to this work benefit you? Let us know!

\section{Recommended Citation}

Frontiers in Reproductive Health. 2008. "Using operations research to enhance delivery of postpartum/ postabortion family planning services in the Arab region," FRONTIERS Final Report. Washington, DC: Population Council. 


\title{
Using Operations Research to Enhance Delivery of Postpartum/Postabortion Family Planning Services in the Arab Region
}

Frontiers in Reproductive Health (FRONTIERS)

Population Council

\author{
September 2008
}

This study was made possible through the generous support of the people of the United States through the United States Agency for International Development (USAID), under the terms of Cooperative Agreement No. HRNA-00-98-00012-00 and In-house project 5800 53125. The contents of this report are the responsibility of the FRONTIERS Program and do not necessarily reflect the points of view of USAID or the United States Government.

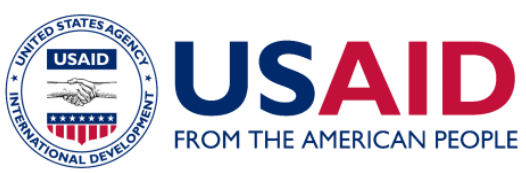

(P) Population Council FRONTIERS 


\section{EXECUTIVE SUMMARY}

Over the last ten years FRONTIERS has worked in many countries to integrate family planning services within postpartum and postabortion care services in order to help women achieve healthy birth intervals. The FRONTIERS program in Cairo organized a two-and-half day workshop to share programmatic experiences and lessons learned in integrating family planning with service providers from Egypt, Jordan, Sudan, and Yemen representing mid-level program managers and researchers. The workshop was held on March 25 - 27, 2008 in tandem with a national end of project seminar for stakeholders in Egypt. The workshop was largely participatory and combined plenary sessions, discussions and working groups, with objectives to enhance utilization of those best practices and to increase their impact.

Throughout the presentations and discussions, participants emphasized the need to capture missed opportunities in antenatal, delivery, postpartum or postabortion care by providing family planning services in all encounters between women and the health care system. They also agreed on an overarching need for operations research in assisting policy makers and program managers in selecting model(s) of integration best suited for the individual local settings. 


\section{CONTENTS}

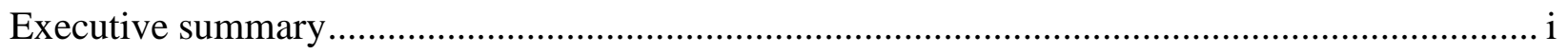

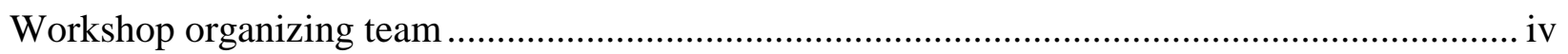

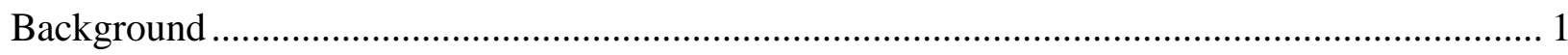

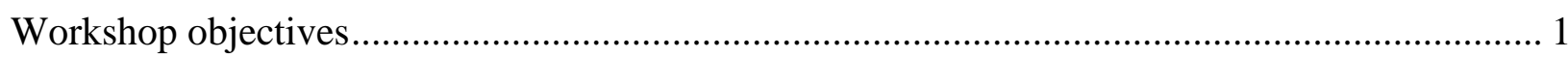

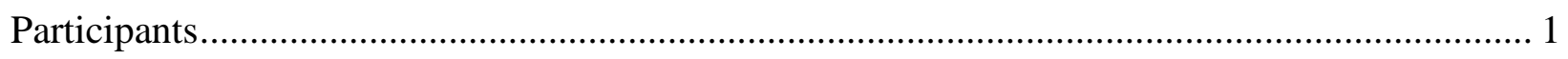

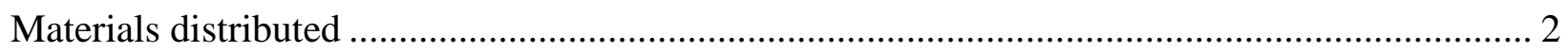

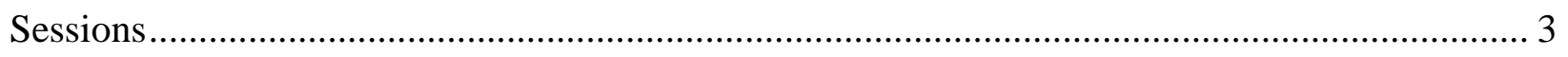

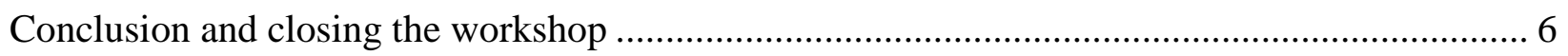

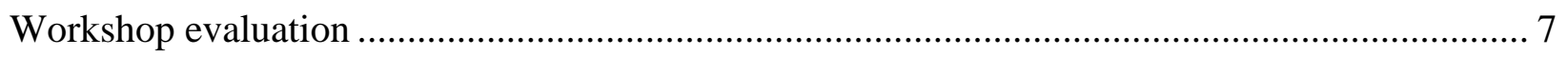

Appendix A: List of participants.................................................................................... 8

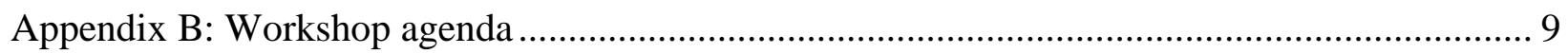

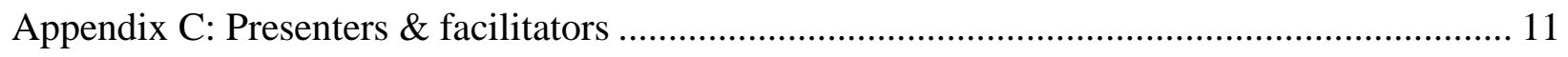

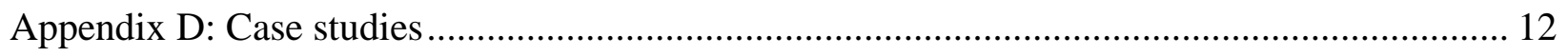

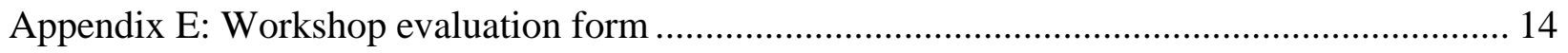




\section{ACKNOWLEDGEMENTS}

The FRONTIERS Program is grateful to all those who made this regional workshop possible. We wish to thank the presenters and the facilitators for sharing their knowledge and expertise with participants in order to strengthen postpartum/postpartum family planning programs in the region. We are also grateful to the participants for their interest and active participation, and for enriching the workshop discussions with their opinions and experiences. Last but not least, we wish to thank USAID/Washington, USAID/Egypt and USAID / Jordan for supporting participants to attend the workshop. 


\section{WORKSHOP ORGANIZING TEAM}

Workshop Organizer

Dr. Nahla Abdel-Tawab

FRONTIERS Regional Advisor

Technical committee

Dr. Maha El-Rabbat

Professor of Public Health

Dr. Maali Guimei

Professor of Nursing

Dr. Ezzeldin Osman

Professor of $\mathrm{Ob} / \mathrm{Gyn}$

Logistical and Administrative support

Gihan Hosny

FRONTIERS Program Administrator

Sarah Ismail

Intern

Nervana Thabet

Temp. Administrative Assistant 


\section{BACKGROUND}

Over the last ten years, FRONTIERS has implemented a large number of operations research (OR) studies in many developing countries to increase access, quality and use of family planning services, with the aim of reducing unplanned or unwanted pregnancies. FRONTIERS has worked extensively on integrating family planning services within postpartum and postabortion care services, to assist women in achieving healthy birth intervals. These projects have produced many important findings and programmatic implications (including configuring services for postpartum/postabortion clients, the most appropriate type and content of training, and strengthening supervision systems) with regional and global significance. Projects conducted in Egypt and the West Bank and Gaza are of particular relevance to countries in the Arab region that have higher levels of unmet need and fairly new RH/FP programs.

To build upon this experience, the FRONTIERS program in Cairo, Egypt organized a two-andhalf day workshop to share programmatic experiences and lessons learned in integrating family planning and postpartum/postabortion, with mid-level program managers and researchers from several countries in the Arab region.

\section{WORKSHOP OBJECTIVES}

- To increase understanding of the importance of integrating postpartum/postabortion care with family planning services, in efforts to improve the health of mothers and children in the Arab region;

- To share best and promising practices in providing family planning services, especially those within postpartum and postabortion care;

- To orient participants in adapting best and promising practices in their own programs through practical sessions and working groups;

- To recognize the role of operations research in enhancing the integration of family planning services with postpartum/postabortion care.

\section{PARTICIPANTS}

The workshop was attended by a total of 21 participants: from Egypt ( 9 participants), Jordan (5 participants), Sudan (1 participant), and Yemen (6 participants). Participants comprised of midlevel program managers and researchers, representing governmental organizations, NGOs, academic institutions, cooperating agencies (CAs) and donors ${ }^{1}$. The selection of workshop participants was conducted in coordination with USAID missions of the above countries. A list of workshop participants is attached in Appendix A.

\footnotetext{
${ }^{1}$ FRONTIERS did not cover travel costs of participants from CAs or donor agencies.
} 


\section{MATERIALS DISTRIBUTED}

All participants received a workshop bag that included the following materials: - A CD entitled "Postpartum/postabortion family planning: Toolkit for managers and researchers" incorporating job aids, IEC materials and other materials developed by FRONTIERS in its postpartum/postabortion care work. The $\mathrm{CD}$ was divided into the following sections:

$\circ$ Introduction and description of contents

- Service delivery protocols, including: protocol for providing PP/PA FP services in hospital based settings, protocols for PP home visits by $\mathrm{MCH}$ nurses and $R R s$

- Training materials, including: protocols for training providers in hospital based settings and primary health care settings

- IEC materials, including: a wall chart for day 40 visit, and a PAC brochure for care after discharge

○ Monitoring checklists, including: antenatal care checklist, postpartum home visits checklist

- References of reports and publications on postpartum/postabortion care produced by Population Council in Egypt and other countries.

- Related links, such as Population Council links and other external links with resources on postpartum/postabortion care.

- A manual in Arabic entitled "Providing family planning services to postpartum and postabortion women: A manual for program managers and researchers", which summarizes best practices and lessons learned in offering family planning service to postpartum/ postabortion women. Information in the manual was based largely on FRONTIERS' Program Brief Meet the Health Needs of Mothers and Children in the Postpartum Period (Vernon et al., 2008), and Postabortion Care Global Resources: A Guide for Program Design, Implementation and Evaluation developed by the USAID PAC Working Group (2007).

- Selected FRONTIERS publications on linking family planning with postpartum/postabortion care in Egypt and India.

- Booklets on designing family planning operations research, produced by the Population Council (Fisher et al, 1998).

- A CD with all End of Project Seminar and workshop presentations.

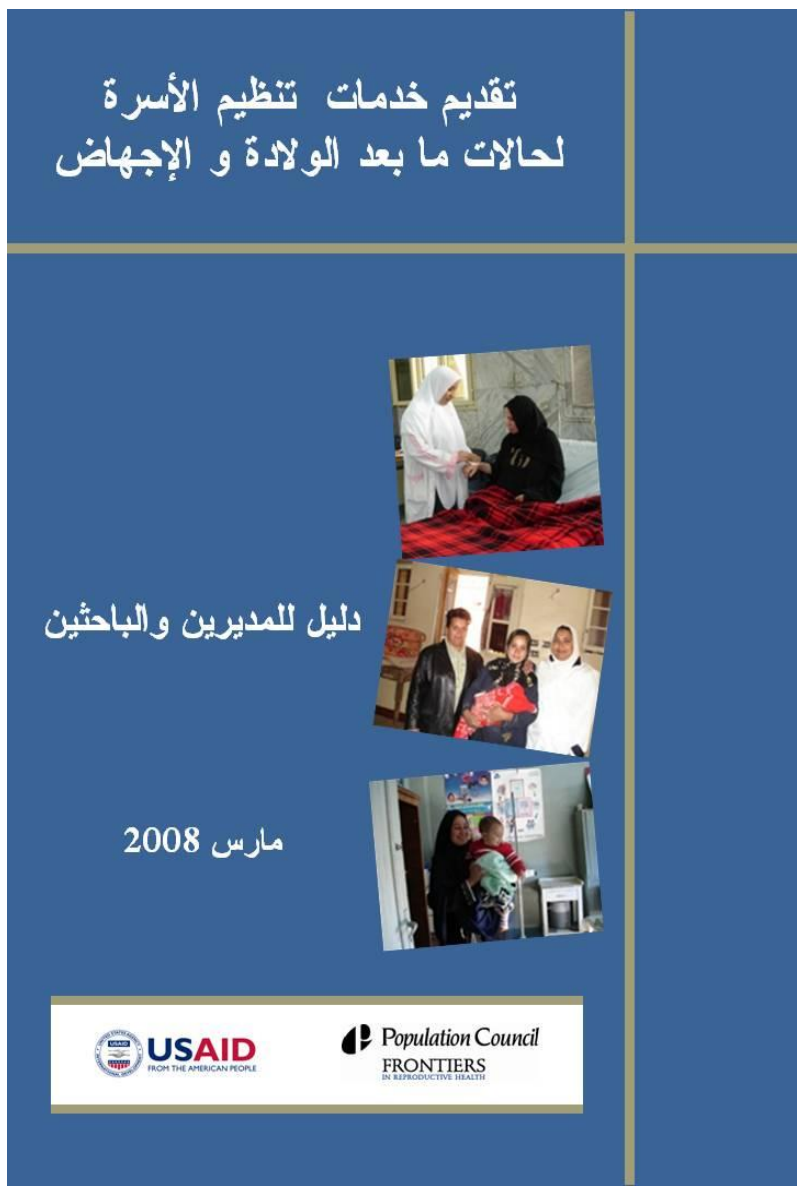




\section{SESSIONS}

The workshop was preceded by a national End of Project Seminar for the FRONTIERS project, setting the stage for the workshop. This seminar provided the rationale for integration, potential integration models and lessons learned from previous programs integrating postpartum / postabortion with family planning services. Of particular relevance in this seminar were the following two presentations: "Meeting contraceptive needs of mothers in the postpartum period: Lessons from FRONTIERS experiences globally" by Dr. Ian Askew (FRONTIERS Director); and "Strengthening postabortion care services in Egypt: Moving from research to program" by Dr. Nahla Abdel-Tawab (FRONTIERS Regional Advisor).

Askew's presentation made the case that the provision of postpartum family planning services is important because it will help women achieve healthy timing and spacing of pregnancy, reduce infant death and address postpartum women's unmet need for family planning, which reaches up to 70 percent by 12 months postpartum. The presentation discussed several models of providing postpartum family planning services, namely at place of delivery and before discharge, at health clinics providing antenatal and postpartum care, through community based programs and multilevel programs. The presentation concluded that postpartum family planning services could be provided effectively by establishing of fertility intentions during antenatal care and delivery, and that postpartum contacts for maternal and child health can be used to provide family planning services.

Abdel-Tawab's presentation highlighted the importance of providing postabortion family planning services using statistics that demonstrated the magnitude of unsafe abortion and the high percentage of unplanned/unwanted pregnancies among women postabortion. Lessons learned from a number of FRONTIERS studies and from the Asia and Near East Operations Research and Technical Assistance Project (ANE OR/TA project) were also reviewed. In these case studies, improvements in postabortion care (including family planning counseling) were demonstrated to be associated with a greater intention to use family planning after hospital discharge. This presentation highlighted the continued need for intensive training and supervision to enhance provider motivation and commitment to offering integrated services.

The sessions for the regional workshop were divided into five plenary sessions and three working group sessions, all participatory with ample time for discussion. The sessions focused on issues and barriers faced when providing postpartum/postabortion family planning and the possible solutions to these issues. A copy of the workshop agenda and list of presenters is attached in Appendix B and C.

The inauguration of the workshop was held in the evening of March $25^{\text {th }}$ and included an introduction and presentation of workshop objectives by Dr. Nahla Abdel-Tawab, Dr. M.E. Khan (FRONTIERS Director for the Asia and Near East region) and Dr. Ian Askew. Participants were interested in learning about other countries' experiences and the application to their respective country programs. Some topics of particular interest included: how to capitalize on missed opportunities in hospital settings; how to make policy makers aware of the importance of PP/PA FP; and how to improve counseling in postpartum care. 
The first technical session took place on March $26^{\text {th }}$ and included presentations by the four country teams. Overviews of their socio-demographic characteristics and postpartum / postabortion services were provided, and program similarities and differences were discussed. For example, both Egypt and Jordan have fairly high contraceptive prevalence rates (59 percent and 57 percent respectively) but also high contraceptive discontinuation rates (32 percent in Egypt and 44 percent in Jordan). More than half of deliveries in Egypt (56 percent), and almost all deliveries in Jordan (99 percent), take place in health facilities. Yet important to note is that these facilities are not providing routine postpartum family planning services. In contrast, Sudan and Yemen have younger family planning programs, total fertility rates of 4.4 in Sudan and 6.2 in Yemen, and contraceptive prevalence rates of 7.6 percent and 13 percent respectively. The percentage of women receiving antenatal care in these countries is approximately 70 percent in Sudan and 48 percent in Yemen, and around three quarters of women deliver in the home.

It was clear from the presentations that all four countries would benefit greatly from an integrated postpartum/postabortion family planning system. However, given the different country settings and national contexts, it was clear from the statistics that no single model would suffice. It was suggested that Egypt and Jordan give priority to hospital-based PP/PA FP programs and Sudan and Yemen should emphasize community-based deliver of their integrated program. The following presentations were made to help participating countries identify specific components to include in their programs.

Abdel-Tawab provided a presentation in the second session, reviewing models of program integration for family planning and postpartum/postabortion care services. After discussion, participants agreed to the following:

- Postpartum family planning services should start during antenatal care with effective linkages between antenatal care services, delivery services and postpartum care services.

- No opportunity for discussing family planning with clients should be missed, e.g. during immunization sessions.

- The first postpartum visit to the clinic should combine services for the mother and the newborn, to be more attractive and less burdensome for mothers.

- There is a need for a counter-referral mechanism between hospital-based services and primary health care services to ensure adequate follow-up of postpartum and postabortion women after discharge, and their receipt of a family planning method in due time.

During the second session, Dr. M.E. Khan explained the uses of OR in helping program managers identify and diagnose service delivery problems and how to test alternative solutions. He discussed what distinguishes OR from other types of research, the steps of conducting operations research, different study designs, and mechanisms to enhance utilization of results. There was also a group exercise offering case studies and problem solving experience to participants_examples of these are attached in Appendix D.

Session three included discussion of service delivery guidelines to provide comprehensive postpartum/postabortion care. Dr. Alaa El-Fekky described components of postpartum care and emphasized the need for them to be comprehensive, regardless of the place of delivery. Dr. Ezzeldin Osman described the elements associated with expanding the PAC model, namely: 
- Community and service provider partnerships for the prevention of unwanted pregnancies and unsafe abortion,

- Counseling to identify and respond to women's emotional and physical health needs,

- Treatment of incomplete abortion,

- Family planning services, and

- $\quad$ Reproductive and other health services.

Examples of enhanced postabortion care — such as, husband involvement, wide range of FP methods, and availability of IEC materials to answer clients' questions or concerns-were included in the workshop as well. Dr. Maali Guimei, presented counseling guidelines, needs of postpartum and postabortion women, advantages and disadvantages of providing family planning counseling to women at different times, and the issues related to provision of PP/PA FP services is completed efficiently -i.e. ensuring the woman's informed consent, where to provide services, when and by whom.

Some obstacles associated with the provision of postpartum/postabortion family planning services were discussed. The high workload and the appropriate service providers were addressed; the use of the postpartum/postabortion IUD was also covered. Participants addressed the training necessary, device removal, and follow-up services associated with providing the IUS. The role of the husband and his influence on family planning decision-making was discussed, additional to the need for changing hospital policies to encourage family planning counseling for both men and women. Lastly, the timing of FP service provision was addressed, as discharge from the hospital varies. One option mentioned was the potential for hospitals to require women to stay for at least 24 hours after delivery or postabortion care (if patient receives general anesthesia), to provide women adequate time to consider family planning and manage possible complications. The session emphasized the flexibility and applicability of these recommendations for each individual setting, as well as the possible adjustments needed for large-scale implementation.

The final day of the workshop included discussion on two main issues: the role of men in postpartum/postabortion care and, monitoring and evaluation of programs. Dr. Hala Youssef highlighted the benefits of involving husbands in postpartum/postabortion care using results of FRONTIERS research. Studies conducted in Egypt, West Bank and Gaza, and India showed that involving men through counseling and service provision was associated with positive outcomes for women (such as increased use of contraception, improved recovery, and increased utilization of services). Barriers identified to interfere with men's involvement include cultural values discouraging their involvement, hospital procedures prohibiting men in the Ob/Gyn ward, clinic hours that are unsuitable for men's schedules, and inadequate provider skills for counseling men.

Participants made the following suggestions to improve male involvement in PP/PA care:

1. Mass media and school curricula should promote male participation and responsibility in reproductive health;

2. Hospitals and clinics should designate hours for men to be present with their wives, and if possible conduct joint counseling ANC/PNC care and postpartum contraception at that time, if so desired; 
3. Providers should be encouraged to offer family planning counseling to husbands of postpartum/postabortion women without compromising the women's rights to autonomy and informed choice;

4. Physicians, nurses and community health workers should be trained to properly counsel men and enlist their support of family planning;

5. IEC materials can be used to reach men, e.g. fliers, brochures, and lectures/seminars in their work places.

Dr. Madiha Said gave a presentation discussing basic principles of monitoring and evaluation and its application to postpartum/postabortion family planning programs. "Good" indicators were identified and explained. An interactive session was held to allow participants to identify the details associated with good monitoring and evaluation, and how to obtain data for specific indicators.

Working group exercises took place, during which participants gained hands-on experience in integrating family planning into existing postpartum and postabortion care programs using examples of interventions presented and drawing on the lessons learned and recommendations from the previous two days. Groups received a case study of a hypothetical country with distinctive characteristics and service delivery problems related to reducing unwanted or closely spaced pregnancies. Participants in each group were asked to design a PP/PA FP program specifically addressing the needs of that country. At the completion of the session, participants presented an outline of their case study and mock-program plan. Each case presentation included aspects of the topics reviewed through the entire workshop. The three case scenarios and related program questions are attached in Appendix D.

\section{CONCLUSION AND CLOSING THE WORKSHOP}

Concluding remarks were made by Abdel-Tawab and Askew, who re-emphasized the need to capture missed opportunities in antenatal, delivery, postpartum or postabortion care and to provide family planning services in all encounters within the health care system. While OR studies have shown provision of family planning services associated with greater acceptance, no single model of integration is good for all countries and all health settings. Operations research can assist policy makers and program managers in selecting the most appropriate model(s) for providing services in the most effective and efficient manner.

Participants requested copies of the updated postpartum /postabortion care guidelines, as well as training materials for their respective service providers. An electronic communication group will be formed among workshop members to exchange documents, experiences and lessons learned, with the aim of fostering collaboration and enhancing quality of services. It is hoped that this group will expand to become a regional network, will lead the integration efforts and contribute to reducing rates of unintended and closely spaced pregnancies in the Arab region. The workshop was concluded by handing participants certificates of completion and by taking a group photograph. 


\section{WORKSHOP EVALUATION}

During the final session of the workshop participants were asked to fill out an evaluation, assessing several aspects of the workshop-speakers, topic choice, working groups. A copy of the workshop evaluation form is attached in Appendix E.

In general participants rated the workshop positively and almost all of them (19/20) stated that it will help them do their work better. The most commonly mentioned suggestions for improving future workshops were: to increase number of days; to allow more time for discussion; and to provide information on the steps involved in actual implementation of PP/PA FP programs. 


\section{APPENDIX A: LIST OF PARTICIPANTS}

Egypt
\begin{tabular}{|l|l|l|}
\hline Name & Title & Organization \\
\hline \hline Dr. Amal Zaki & Program Director of Raedat Reefiyat & MOHP \\
\hline Dr. Atef Elshetany & $\begin{array}{l}\text { General Manager of Governmental } \\
\text { Family Planning Services } \\
\text { Adminisrattion }\end{array}$ & MOHP \\
\hline $\begin{array}{l}\text { Dr. Mohammed Nour El } \\
\text { Din }\end{array}$ & Interim Director of MCH Care & MOHP \\
\hline Dr. Laila Soliman & visoMedical Superr & $\begin{array}{l}\text { Egyptian Family Planning } \\
\text { Association }\end{array}$ \\
\hline Dr. Tarek El Mahlawy & Assistant Director of Curative Care & MOHP \\
\hline Dr. Saied Ibrahim & OB/GYN Specialist & Almatareya Teaching Hospital \\
\hline Dr. Gamila Ahmed & Director of MCH Care & Giza Health Directorate \\
\hline Dr. Ibrahim Kharboush & Professor of MCH & $\begin{array}{l}\text { Institute of Public Health - } \\
\text { Alexandria }\end{array}$ \\
\hline
\end{tabular}

\section{Jordan}

\begin{tabular}{|l|l|l|}
\hline Name & Title & Organization \\
\hline Dr. Ali Khalil Arbaji & Project Management Consultant & $\begin{array}{l}\text { USAID - Population and Family } \\
\text { Health Office }\end{array}$ \\
\hline Ms. Huda Munjed Murad & RH Task Manager & $\begin{array}{l}\text { Health Systems Strengthening } \\
\text { Project (HSS), Jordan }\end{array}$ \\
\hline Dr. Sabry Hamza Kareem & Safe Motherhood Team Leader & $\begin{array}{l}\text { Health Systems Strengthening } \\
\text { Project (HSS), Jordan }\end{array}$ \\
\hline Dr. Eissa AlMasarweh & Professor of demography & Jordan University \\
\hline Dr. Salma Zu'bi & Director of Medical Services & $\begin{array}{l}\text { Jordanian Association for Family } \\
\text { Planning }\end{array}$ \\
\hline
\end{tabular}

\section{Sudan}

\begin{tabular}{|l|l|l|}
\hline Name & Title & Organization \\
\hline Ms. Sara Musa & Country Program Manager & Population Council \\
\hline
\end{tabular}

\section{Yemen}

\begin{tabular}{|l|l|l|}
\hline Name & Title & Organization \\
\hline \hline Dr. Abdelmegeid Farhan & Secretary General & CSSW Yemen \\
\hline Dr. Bothaina Attal & $\begin{array}{l}\text { Associate Professor of Community } \\
\text { Medicine }\end{array}$ & San'aa Medical University \\
\hline Dr Entesar Alsaidi & $\begin{array}{l}\text { Associate Professor of Community } \\
\text { Medicine }\end{array}$ & San'aa Medical University \\
\hline Dr. Fawzeya Babeid & GYN Department/Director of OB & AlThawra Hospital \\
\hline Dr. Samira Saed & Director Reproductive Health & MOHP \\
\hline Ms. Samera Taher & Director of Family Planning & MOHP \\
\hline
\end{tabular}




\title{
APPENDIX B: WORKSHOP AGENDA
}

\author{
Shepheard Hotel \\ (March 25-27, 2008)
}

Nefertiti Room

\section{Tuesday March 25, 2008 \\ 17:30 - 18:30 Inauguration of regional PP PA FP workshop \\ Introductions and workshop objectives}

\begin{tabular}{|c|c|}
\hline \multicolumn{2}{|c|}{ Wednesday March 26, 2008} \\
\hline $\begin{array}{l}\text { 9:00 }-\mathbf{1 0 : 0 0} \\
\text { 9:00-9:15 } \\
9: 15-9: 30 \\
9: 30-9: 45 \\
9: 45-10: 00\end{array}$ & $\begin{array}{l}\text { Overview of postpartum / postabortion services in participating countries: opportunities } \\
\text { and challenges } \\
\text { Egypt } \\
\text { Jordan } \\
\text { Yemen } \\
\text { (Discussion) }\end{array}$ \\
\hline $\begin{array}{l}\text { 10:00 - 11:00 } \\
\text { 10:00 - 10:30 } \\
10: 30-11: 00\end{array}$ & $\begin{array}{l}\text { Models of integrating FP into postpartum / postabortion care } \\
\text { (Discussion) } \\
\text { Dr. Nahla Abdel Tawab }\end{array}$ \\
\hline 11:00 - 11:30 & Break \\
\hline $\begin{array}{l}\text { 11:30-12:45 } \\
11: 30-12: 00\end{array}$ & $\begin{array}{l}\text { Role of operations research in integrating family planning within postpartum / } \\
\text { postabortion care } \\
\text { Dr. M. E. Khan }\end{array}$ \\
\hline $12: 45-1: 00$ & Introduction to working groups \\
\hline $1: 00-2: 30$ & Working groups \\
\hline $2: 30-3: 30$ & Lunch \\
\hline $3: 30-5: 30$ & $\begin{array}{l}\text { Guidelines for integrating family planning within postpartum / postabortion care } \\
\text { Guidelines for integrated postpartum care }\end{array}$ \\
\hline $3: 30-3: 50$ & $\begin{array}{ll}\text { Guidelines for integrated postabortion care } & \text { Dr. Alaa El Feky }\end{array}$ \\
\hline $3: 50-4: 10$ & $\begin{array}{ll}\text { Counseling of postpartum / postabortion women } & \text { Dr. Ezzeldin Osman Hassan }\end{array}$ \\
\hline $\begin{array}{l}4: 10-4: 30 \\
4: 30-5: 30\end{array}$ & (Discussion) \\
\hline $7: 30-9: 00$ & Dinner at Al-Azhar Park \\
\hline
\end{tabular}




\section{Omar El-Khayyam Room}

\begin{tabular}{|c|c|}
\hline $\begin{array}{l}\text { 9:00-10:15 } \\
9: 00-9: 30 \\
9: 30-10: 15\end{array}$ & $\begin{array}{l}\text { Men: the missing link in postpartum / postabortion care } \\
\text { (Discussion) }\end{array}$ \\
\hline $\begin{array}{l}10: 15-11: 30 \\
10: 15-10: 30 \\
10: 30-11: 30\end{array}$ & $\begin{array}{l}\text { Monitoring and supervision of postpartum / postabortion family planning services } \\
\text { (Exercises) }\end{array}$ \\
\hline 11:30-12:00 & Break \\
\hline 12:00 - 2:00 & Working groups \\
\hline 2:00-3:00 & Lunch \\
\hline $3: 00-4: 00$ & Resume working groups \\
\hline 4:00-5:00 & Group presentations \\
\hline $5: 00-5: 15$ & Workshop evaluation and closing remarks \\
\hline
\end{tabular}




\section{APPENDIX C: PRESENTERS \& FACILITATORS}

Dr. Nahla Abdel-Tawab

FRONTIERS Regional Advisor

Population Council

Cairo - Egypt

Dr. Ian Askew

FRONTIERS Program Director

Population Council

Nairobi - Kenya

Dr. Alaa El-Feky

Ob/Gyn Professor

Ain Shams University

Cairo - Egypt

Dr. Maha El-Rabbat

Professor - Public Health Depart.

Faculty of Medicine

Cairo University

Cairo - Egypt

Dr. Maaly Guimie

Professor

Faculty of Nursing

Alexandria University

Alexandria - Egypt
Dr. M. E. Khan

Regional Associate Director, FRONTIERS

Population Council

New Delhi - India

Dr. Ezz Eldin Osman

Executive Director

Egyptian Fertility Care Foundation

Cairo - Egypt

Dr. Madiha Said

Professor - Public Health Depart.

Faculty of Medicine

Cairo University

Cairo - Egypt

Dr. Hala Youssef

Professor - Public Health Depart.

Faculty of Medicine

Cairo University

Cairo - Egypt 


\section{APPENDIX D: CASE STUDIES}

\section{Exercise for Working Groups}

\section{Case Study (1):}

Women in country (X) give birth to about 7 children on average during their reproductive life, which represents two children more than desired. Only $30 \%$ of married women in reproductive age use family planning methods. The women's knowledge about family planning methods is low as the percent of women who know at least 3 family planning methods does not exceed $40 \%$. Abortion is prohibited in Country X except for the cases in which pregnancy poses a risk to the life of the mother. An increase in numbers of incomplete and unsafe abortion cases has been noticed but those cases only represent part of the actual abortion problem.

Postabortion care in hospitals only addresses emergency treatment of the case (i.e.: evacuation by management of bleeding and other problems). Service providers who manage postabortion women are trained to deal exclusively with the emergency condition, without providing any kind of counseling.

Program managers who are concerned about women's health are considering designing a program to link family planning with postabortion care services.

The district health manager invited your group to help her address this situation. As a group of experts, please answer the following questions:

\section{Case study (2):}

The research results in country (Y) indicate that less than $50 \%$ of recently delivering mothers had received antenatal care. Most deliveries in country Y take place at home while only $10 \%$ of women visited health units on the 40th day. This country has a postpartum home visits program but it is not functioning effectively. It was noticed that perinatal mortality rate is on the rise in this country, mainly as a result of short birth spacing intervals.

Program managers who are concerned about women's health are considering designing a program to link family planning with postpartum care services.

The district health manager invited your group to help her address this situation. As a group of experts please answer the following questions:

\section{Case Study (3):}

In Country (Z), a high percentage of deliveries take place in hospitals e.g. public, private or university hospitals, and this is due to the increased women's awareness of the importance of receiving specialized care during delivery. However, care provided to those women consists only of delivering the baby and managing any complications. Women are usually discharged from the hospital few hours after delivery if there are no maternal or newborn complications. 
Women do not necessarily receive prenatal or postpartum care in the same hospital where they deliver. In fact, the data has shown that $80 \%$ of women go to the primary health care units to receive prenatal or child care services. On the other hand, a large percentage of women have an unplanned pregnancy in less than 2 years after the previous birth. The majority of women in country $(\mathrm{Z})$ depend on breast feeding as a method of birth spacing.

Program managers who are concerned about women's and child health are considering designing a program to link family planning with postpartum care services. The district health manager invited your group to help her address this situation. As a group of experts please answer the following questions:

\section{Questions for operations research exercise}

1. What service delivery problems are presented in this case?

2. The working group is asked to identify and define one operations research study to be conducted to support integration of family planning services into postpartum/postabortion services.

3. What are the research questions that will be addressed by the study?

4. What is the kind of study to be used? Diagnostic / intervention / evaluation

5. What is the plan for disseminating results? Who are the target audiences? What are the communication channels for each audience?

\section{Questions for program design exercise}

In light of the case study and results of the conducted operations research, please answer the following questions:

1. What is the most appropriate model for integrating family planning services and postpartum/postabortion services? Why?

2. What are the components of the program with specifying the roles?

3. What are the resources needed (human, infrastructure, IEC material, job aids)?

4. What would you do to increase demand for services?

5. What is the existing training system and the one that is proposed?

6. What is the proposed supervision system?

7. What other services to coordinate and collaborate with?

8. What is the proposed monitoring system and indicators suggested (Input, process, output, outcome and impact indicators and source(s) of data)?

9. What are the challenges that might be faced by the program and how do you expect to overcome them? 


\section{APPENDIX E: WORKSHOP EVALUATION FORM}

1-Kindly mark the box that expresses your opinion in the following subjects:

\begin{tabular}{|l|c|c|c|}
\hline & Excellent & Good & Poor \\
\hline Venue of the meetings & $\square$ & $\square$ & $\square$ \\
\hline Speakers & $\square$ & $\square$ & $\square$ \\
\hline Subjects & $\square$ & $\square$ & $\square$ \\
\hline Presentations & $\square$ & $\square$ & $\square$ \\
\hline Work Groups & $\square$ & $\square$ & $\square$ \\
\hline $\begin{array}{l}\text { Participation and } \\
\text { Discussion }\end{array}$ & $\square$ & $\square$ & $\square$ \\
\hline Publications & $\square$ & $\square$ & $\square$ \\
\hline Meals and Coffee breaks & $\square$ & $\square$ & $\square$ \\
\hline $\begin{array}{l}\text { The General Organization } \\
\text { of the Workshop }\end{array}$ & $\square$ & $\square$ & $\square$ \\
\hline
\end{tabular}

2-Do you think that you will get benefit in your work from attending this workshop?

$$
\text { Yes No }
$$

Kindly illustrate:

3- How can we conduct this workshop in a better way in the future? 